\title{
The Consequences of the Military Conflict in Eastern Ukraine, Its Impact on International Investment Attractiveness, Economic and Demographic Development in Ukraine
}

\author{
Dmytro Vasylkivskyi ${ }^{1}$, Serhii Matiukh ${ }^{2}$, Olha Matviiets ${ }^{1}$, Ihor Lapshyn ${ }^{1} \&$ Vitalina Babenko ${ }^{3}$ \\ ${ }^{1}$ International Economic Relations Department, Khmelnytskyi National University, Ukraine \\ ${ }^{2}$ Vice-Rector for Scientific-Pedagogical Work of Khmelnytskyi National University, Ukraine \\ 3 International E-commerce and Hotel \& Restaurant Business Department, V. N. Karazin Kharkiv National \\ University, Ukraine \\ Correspondence: Vitalina Babenko, Dr.Sci. (habil.) in Economics, PhD in Technical Sciences, Professor (Full), V. N. \\ Karazin Kharkiv National University, 4 Svobody Sq., Kharkiv 61022, Ukraine. Tel: 380-67-570-3573. E-mail: \\ vitalinababenko@karazin.ua
}

Received: June 23, 2020

Accepted: July 30, 2020

Online Published: August 14, 2020

doi:10.5430/rwe.v11n4p81

URL: https://doi.org/10.5430/rwe.v11n4p81

\begin{abstract}
The conflict in the Eastern part of Ukraine and the growing geopolitical tensions have had a significant impact on the economy and society of the country. As a result, it deepened the recession and diverged from the planned development indicators. In particular, this concerns international reserves of the National Bank of Ukraine and the country's budget deficit. Multilateral economic changes, exacerbated by the impact of hostilities in the Eastern part of the country have transformed the structure of socio-demographic processes in Ukraine. Armed confrontation causes a continuous deterioration of demographic and economic indicators of development not only of Donetsk and Luhansk regions, but also has an impact on the whole country. This confrontation is also accompanied by the loss (destruction, theft, etc.) of public assets. The estimated cost of destroyed components of industrial, communal, social, transport, energy and other infrastructure are indicative due to the inability to inspect objects located within the territory controlled by terrorist groups. The conflict has also affected the investment attractiveness of the country, which accelerates the creation of a depressed nature of country's development. Therefore, in the context of hostility in the Eastern Ukraine, it is important to understand and study its destabilizing impact, not only on domestic economic and demographic indicators, but also on the volume of foreign investment, which will allow us to understand the level of country's involvement in the global investment space and the real impact of military action on the population and on international economic affairs of Ukraine. As a result of this scientific research, the population and GDP forecast have been conducted. It is worth noting that the forecast itself based on regression mathematical modelling which includes past data and can be accurate if current conditions are stable in the future.
\end{abstract}

Keywords: military conflict, economy, demography, international investments, impact

JEL Classification: E27, F21, F51

\section{Introduction}

Five years ago, in February, 2014, the Russia broke out the war against Ukraine without any announcement of intention. In violation of the rules and principles of international law, bilateral and multilateral agreements, the Russian Federation annexed the Autonomous Republic of Crimea and Sevastopol, occupied certain areas of Donetsk and Luhansk regions. The approximate number of casualties in Ukraine is estimated between 30 and 35 ths. More than 13 ths. were killed (civilian and Ukrainian military). Nearly $1.5 \mathrm{mln}$. residents of Eastern Ukraine have been forced to leave their homes. The infrastructure of the occupied regions has been destroyed and $27 \%$ of the Donbas industrial potential has been illegally transferred to Russia (State Statistics Service of Ukraine, 2019).

The population is the main factor and driver of the country's economic development and which on the one hand is a component of the productive forces and labor resources of the state, and on the other, the consumer of goods and services, where the main role is played by all available population. The hostilities in the East of the country have led not 
only to the transformation of population demographic processes in quantitative but also to qualitative composition, which is irreversible, and leads to profound structural and systemic shifts in population potential, both in the regions and in the country as a whole, moreover it leads to a decrease of economic development and diminishing of international investment attractiveness of the country. The hostilities in the Eastern part of Ukraine mainly have had a negative impact on economic and demographic situation in the country. The crisis of these elements of the general state system has directly affected the demographic processes, because these elements have a strong interconnection. Consequently, poverty has increased, unemployment, birth and death rates have increased, and expatriates have been emigrated (State Statistics Service of Ukraine, 2019).

It should be noted that today Ukraine at the end of the list and occupies last places among all countries in terms of demographic development. Among the most acute are the problems of medicine and health care. In our country not only the level of population is declining, but what is more dreadful - its quality. Average life expectancy is decreasing; infant mortality is at a critically high level. This is a direct evidence of negative structural transformations. Therefore, we can say that the system of demographic processes in Ukraine, with all its characteristic, is in a protracted and structural crisis. Taking into account the crisis not only in the demographic sphere but also in all other spheres of activity of the country, a negative synergistic effect begins to emerge, which further exacerbates the influence of all factors on demographic and economic development. The system has lost its balance and, due to the inevitable conflict of its structural elements, tries to restore it. We strongly believe that this system requires the intervention and restoration of centralized regulation to overcome the crisis.

Thus, the main factors influencing the level of economic development, foreign investment and demographic sphere in the present conditions are the economic situation, migration policy, and the political and military situation in Ukraine. Hostilities in the East of Ukraine have led to an increase the number of internally displaced persons, informally to more than $1.5 \mathrm{ml}$. people. The situation in the East of the country led not only to the redistribution of the population within the state, but also to the external international migration of Ukrainian citizens (State Statistics Service of Ukraine, 2019; The Ministry of Finance of Ukraine, 2018).

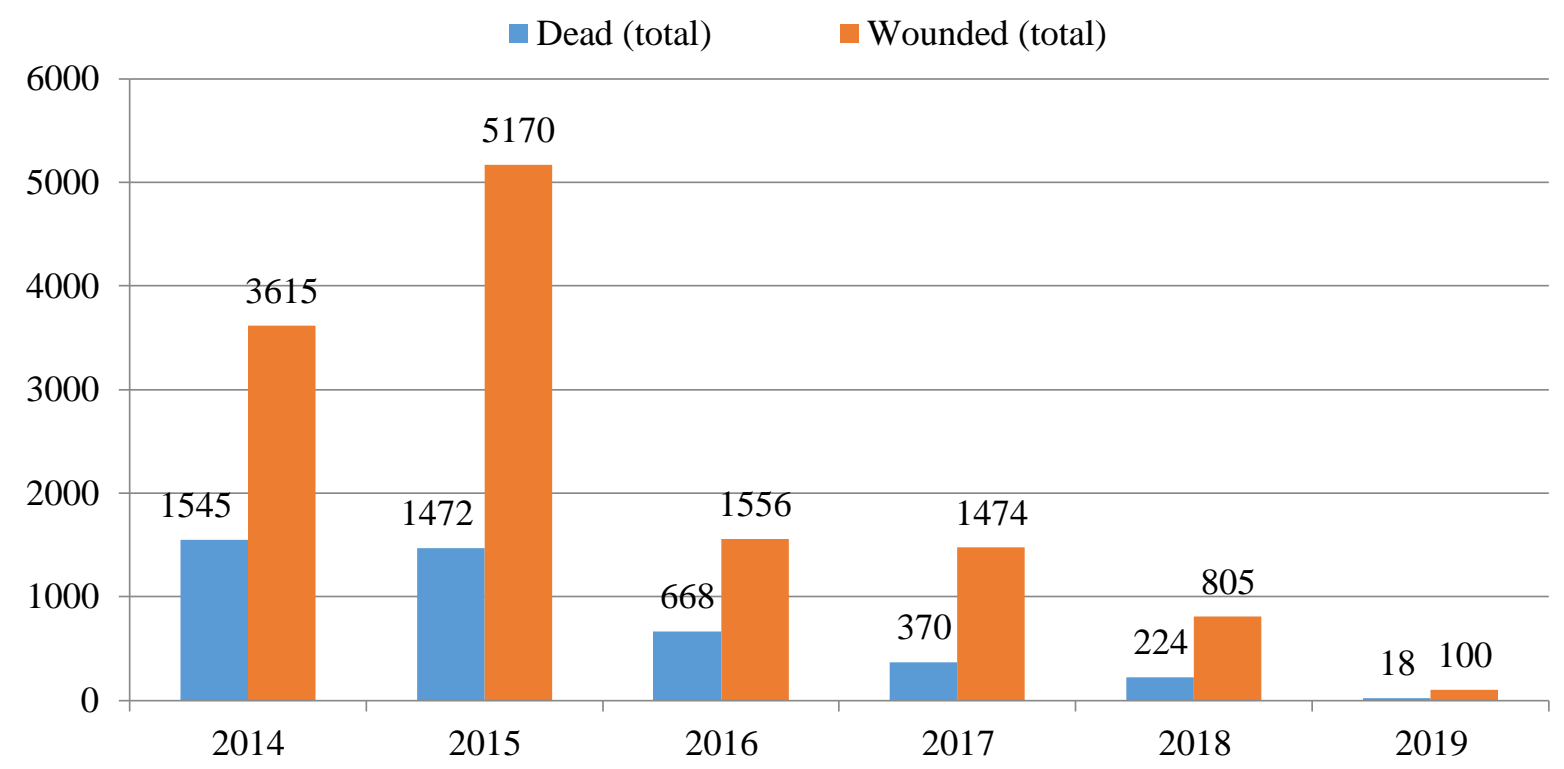

Figure 1. The total number of casualties in the Eastern part of Ukraine

As we can see from the Figure 1, at the start of the hostilities, the casualties were quite significant, but as of 2016, they began to decline, reaching a minimum in 2019. The peak occurred in 2015, when the most violent battles took place. This could have a huge impact on the economy, so to understand the real impact of military action, it is worth considering the economic indicators for the same period. 
Let us turn to a more detailed analysis of hostilities impact on demographic, economic and social processes in the country. The logical assumption is that any military action will destabilize all processes in the country, and have a negative impact on the economy, and thus the process of demography. The hostilities in the Eastern part of the country broke out in 2014.

Therefore, for the sake of analysis, we compare the main economic, social and demographic indicators before the outbreak of hostilities and after external aggression. For comparison, we take data from 2013-2014 and more up-to-date metrics to determine the impact of the destabilizing influx of hostile actions. First, consider economic development indicators, such as the country's GDP, public debt, and foreign direct investment in the country (The Ministry of Finance of Ukraine, 2019). The data are presented at Figure 2.

IIDP in bln. USD

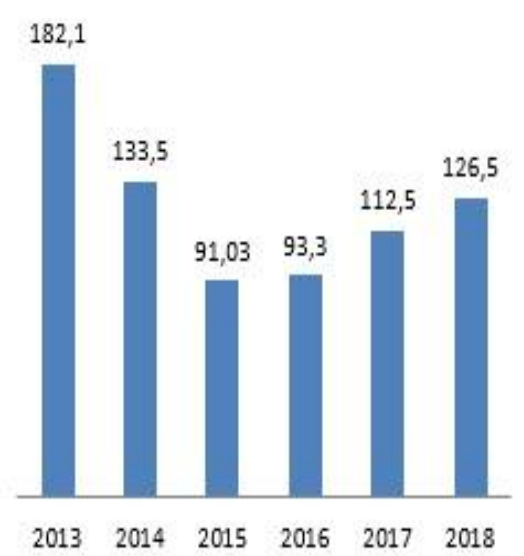

- Foreign direct investment in mln. USD

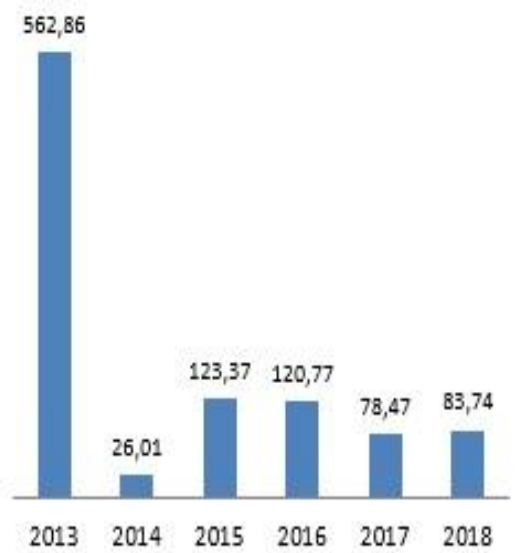

Debt to GDP ratio, \%

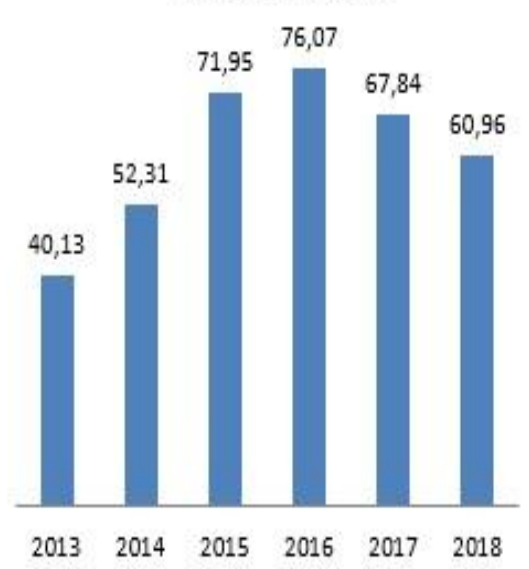

Figure 2. Changes in economic indicators after the hostilities in the Eastern part of Ukraine

As can be seen from Figure 2, it is clear that 2014 started with a rapid deterioration of economic indicators, in particular GDP fell by $26 \%$ at that year, foreign direct investment declined by 20 times, public debt increased by $12 \%$. It is worth noting that the situation has been improving since 2016 , but as the hostilities go on, external investors are skeptical regarding Ukrainian market, as the situation may change at any time.

Besides direct economic indicators we need to research the reaction of Ukrainian government to the situation. Figure 3 shows military and social sphere expenditures. Here are the indicators of state expenditures from the its budget referred to the main indicators of the welfare of the population (State Statistics Service of Ukraine, 2019; The Ministry of Finance of Ukraine, 2018). 


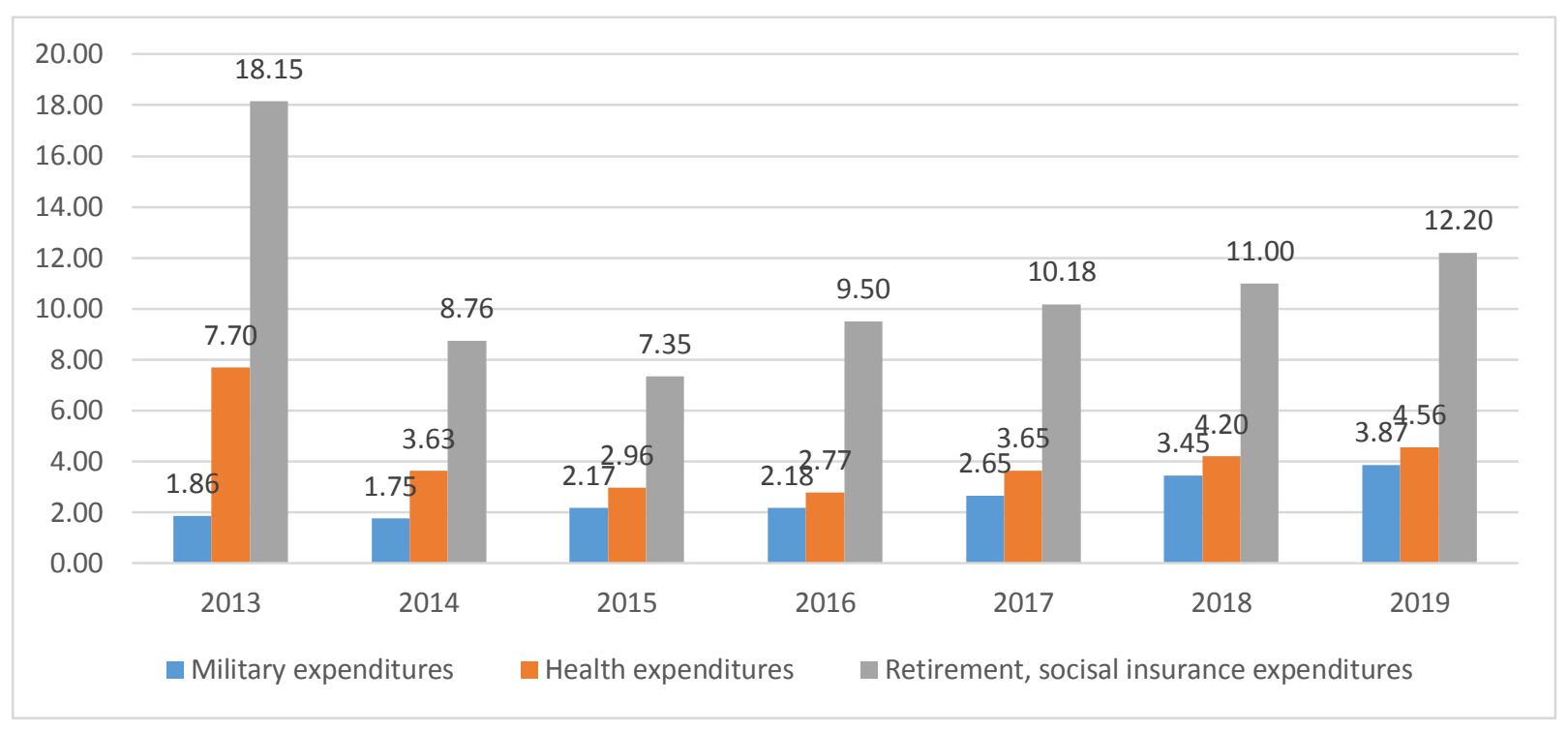

Figure 3. Budget expenditures of Ukraine in billions of USD

As we can see, after the start of hostilities in the Eastern part of the country, the social and healthcare expenditures have been dropped significantly. Which has a negative impact on the welfare of the population of Ukraine. Only the cost of defense has increased since the end of 2014. As a result of unstable situation and the hostilities that led to the economic and social crisis, the processes of population development have got even worse. Thus, the birth rate within the period from 2013 to 2018 fell by $33.31 \%$ compared to 2013503.7 thousand people down to 335.9 thousand people. Mortality within the same period fell by $11.27 \%$ from 662.3 thousand people in 2013 down to 587.6 thousand people in 2018 (State Statistics Service of Ukraine, 2019; The Ministry of Finance of Ukraine, 2018).

There is a correlation between combat casualty rates, birth rates and defense expenditures. Since 2014, 17,000 people have become victims officially, including both dead and wounded. In particular, the correlation coefficient between the death toll and the financing of the armed forces is negative (-0.84), which indicates a strong link. That means, the greater the defense expenditures, the less casualty rates we have. An even stronger connection is traced between the victims of the hostilities and the birth rate. Well, the correlation coefficient is 0.91 . Here, this indicator is explained by the fact that at a time of destabilization and when people do not know what to expect in the future, the birth rate drops, and as long as there are hostilities - we can't expect a radical change in the situation (Podgorna et al,. 2020). The one thing that is really needed is stability, and real change of economic development. Thus, we can conclude that the hostilities are causing chaos in the development of the economy, which in their turn have a negative impact on demographic processes.

Having researched and considered the issues of migration within the country and mainly abroad, we can say that the main reason for the migration of Ukrainian labor migrants, both for short and long term, is the accumulation of financial capital and material assets, gaining experience and contacts.

The impact of migration processes on the demographic sphere is noticeable, but at first glance it is not entirely visible. Ukrainian workers provide their families with relative economic stability, which improves demographics, and also reduces the actual unemployment rate (Babenko et al., 2020). However, now among globalization processes, political and economic shifts in the world - hostilities cause to higher external migration. As it was noted earlier, Ukraine is in a crisis of economic and social development and despite the generally negative dynamics of growth, in recent years the economy has shown a tendency to growth, despite the hostilities in the Eastern part of the country, which strongly interfere and delay the development of the country.

\section{Materials and Methods}

\section{Economic and mathematical modeling}

During the study, the following methods were used: economic-statistical, systemic and comparative analysis - for the analysis of the economic and demographic state of Ukraine, with the purpose of identifying priority areas for increasing economic potential; economic and mathematical modeling, to determine the methodology for the 
development of the strategy of the Ukrainian economic potential which provides the possibility of conducting diagnostics and substantiation of development priorities within the framework of the mathematical regression modeling method. That provides the possibility of establishing the boundaries of the basic parameters of development and determines the interaction of elements of entire economic potential in the process of implementing the strategy in terms of hostilities in the Eastern part of Ukraine.

\section{Functional approximation (FA)}

Usually, a FA problem needs to select some function among a high defined class that nearly matches a target function (TF). There are distinguish two major classes of FA problems: First, for known TF approximation theory is a part of numerical analysis that investigates how certain known functions can be matched or approximated by a certain class of functions (for example, polynomials) that often have their needed properties (integral and limit values, continuity computation, inexpensive, etc.). Second, the TF, let's call it "g", may be unknown; instead of a not obscure formula, only a set of points (a time series) of the form (x, g (x)) can be offered and provided. Using FA, we made a regression based forecast for Ukrainian GDP and population.

\section{Time series (TS) method}

There are two classes that TS analysis methods may be divided into: time-domain and frequency-domain methods. In the time domain, correlation and analysis can be performed in a filter manner using scaled correlation ultimately mitigating the need to operate in the frequency domain. Alternatively, TS analysis techniques usually divided into non-parametric and parametric approaches. The parametric methods presume that the main stationary stochastic process has a specific structure which can be described by few parameters (for instance, using moving average or an autoregressive model). In these methods, the idea is to give the estimation of the model's parameters that describe its stochastic process. From the other side, non-parametric methods apparently estimate the covariance of the process but don't assume that the process has any particular structure. Approaches of TS analysis may also be divided into linear and non-linear, and univariate and multivariate.

\section{Results and Discussion}

The economic crisis has a negative impact on the well-being of the population, which in turn is reflected in the overall state of development of demographic and social processes. As the demographic, political and economic spheres are closely linked, political uncertainty and corruption lead to a crisis in the economic sphere, which in its turn has a negative impact on the demographic sphere. Therefore, we will try to predict changes in the economic sphere in the future and, based on the data obtained, create a scenario for the development of how the changes in the economy caused by hostilities can affect the demographic sphere. As a basis for the forecast we take the GDP of Ukraine at the official exchange rate, that is, the total GDP of the country. The GDP forecast for the following 3 years was created using the method of mathematical regression analysis of dynamic time series, hereinafter - DTS.

TS analysis consists of methods for analyzing TS data in order to get some meaningful statistics of the data. TS forecasting is the use of a model to predict future behavioral values based on previously observed values of an object. Whereas regression analysis is often used to test theories that the current values of one or more independent TS affect the current value of another TS, this type of analysis of TS is not called "TS analysis", which compares values of a single TS or multiple dependent TS at different points in time.

The DTS is a series of chronological sequences of numerical values of a statistical indicator that describes the change in social and economic phenomena over time. Each DTS has two main elements: time " $t$ " and a specific value of indicator (row level) "y". Rows' levels are the indicators whose numeric values make up a dynamic time row. Time is the moment or period to which rows' levels relate. Prediction based on regression models is based on extrapolation, that is, a continuation of the existing trend in the future. In practice, this is can be done by substitution of the next in order parameter value of time to the obtained equation. Let's move on to the analysis. The polynomial trend has the best description of Ukraine's GDP. The value of the approximation reliability, hereinafter - AR is 0.6964 . 


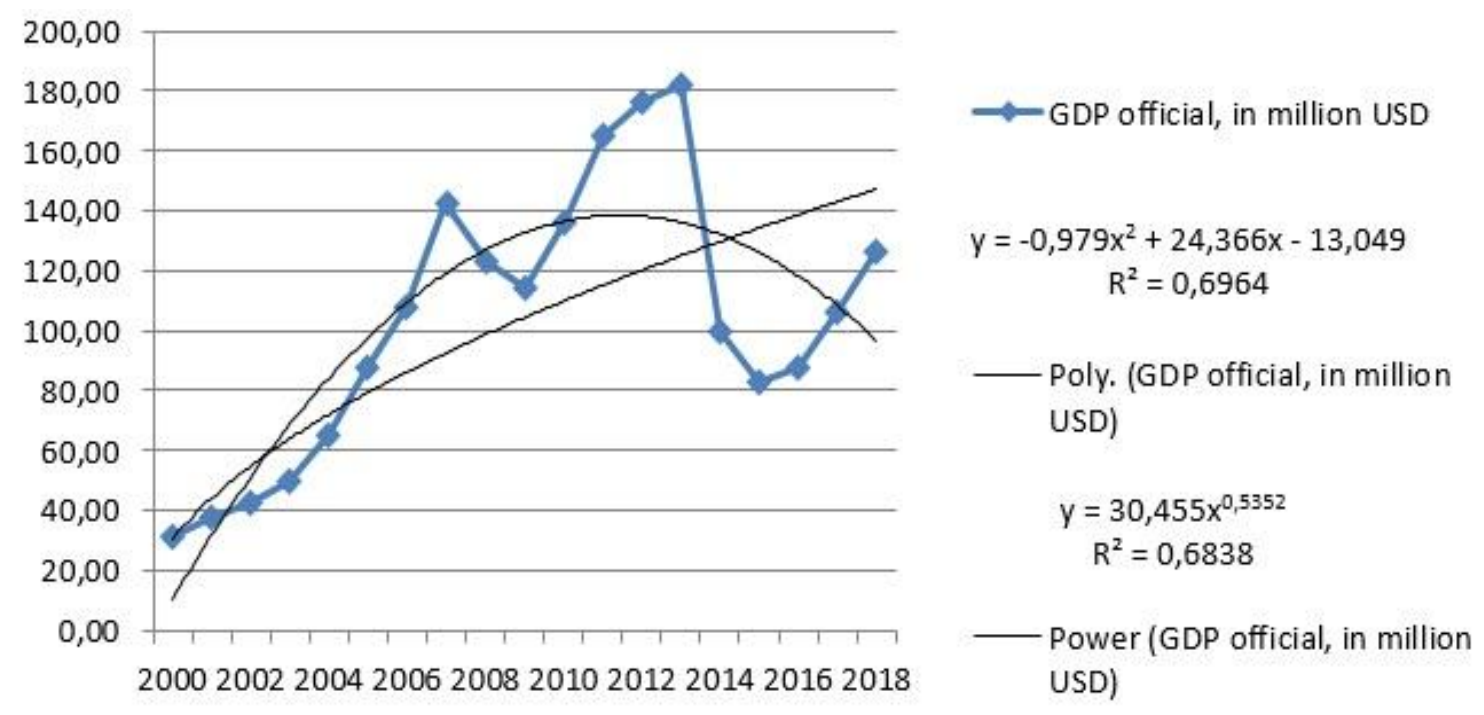

Figure 4. The polynomial and power trend line of Ukrainian GDP

After that we have to change the trend using the following function:

$$
z(t)=y-t r
$$

After changing the trend, we need to perform a harmonic analysis, for this we have to transfer the time into the radial measurement according to the next function:

$$
t^{*}=\frac{2 \pi}{N} t
$$

According to Bessel's functions we find the next coefficients bk, ak, a0: The total number of harmonics is 9 .

$$
\begin{gathered}
a_{0}=\frac{1}{N} \sum_{i=1}^{n} z_{i} ; \\
a_{k}=\frac{\Gamma}{N} \sum_{i=1}^{n} z_{i} \cdot \cos (k t) \\
b_{k}=\frac{2}{N} \sum_{i=1}^{n} z_{i} \cdot \sin (k t)
\end{gathered}
$$

After that we find $\mathrm{z}^{\text {Teor }}(\mathrm{t})$ value by decomposing of the cyclic component output into a Fourier series using the following function:

$$
z^{\text {Teor }}(t)=a_{0}+\sum_{k=1}^{m}\left(a_{k} \cdot \cos (k t)+b_{k} \cdot \sin (k t)\right)
$$

where $\mathrm{m}-$ is the number of harmonics of the Fourier series;

$\mathrm{k}$ - the harmonic number;

$\mathrm{t}$ - time;

$\mathrm{b}_{\mathrm{k}}, \mathrm{a}_{\mathrm{k}}, \mathrm{a}_{0}-$ unknown parameters.

After that we build functional dependency of the $z(t)$ cyclic component and the $z^{\text {teor }}(t)$ of the seasonal component. Visually, we compare the obtained data, and conclude that the curves coincide - it means that everything is correct (Gandhi, Sorabh, Luca Foschini, Subhash Suri, 2010).

We do the same for the second model to make a forecast using a «Power» trend that looks identical. This trend has an approximation reliability «AR» value of 0.6838 .

Then we change the trend that is calculated using function 1. After changing the trend, it is necessary to transfer the time into radial measurement again. 
To transfer a given time into the radial measure we use function 2. According to Bessel's functions we can find bk, ak, a0 coefficients. The total number of harmonics is $19 / 2=9$, here we use functions 3, 4, 5 (S.S. Halli, K.V. Rao, 1992).

The next step is to find $z^{\text {teor }}(t)$ by decomposing the cyclic component's output into a Fourier series using the function 6 . After having built the functional dependency between $z(t)$ and $z^{\text {teor }}(t)$ we compare them visually with each other, and can see that the curves coincide (Temme, Nico M., 1996).

As a result of the analysis of the polynomial and power model we will get a pessimistic and optimistic forecast, but we also need to make a realistic forecast. To construct a model that would be consistent with a realistic estimate, and which would also show a weighted sum of pessimistic and optimistic estimate. We have to determine the weighting factor coefficients that will correspond to the level of adequacy of the models according to the following function:

$$
b_{i}=\frac{R_{i}^{2}}{\sum_{i=1}^{2} R_{i}^{2}}
$$

where $b_{i}$ - weighting factor of $i$ model with the level of adequacy $-R_{i}^{2}$.

For the power model according to the function 7 we get the value of the coefficient which is $-0,4954$, and for the polynomial model we get $-0,5046$.

According to the weighted factors that we have found, the regression realistic model can be calculated by the following function (Ullah, Muhammad Imdad, 2013):

$$
y(x)=b_{1} \cdot y_{1}(x)+b_{2} \cdot y_{2}(x)
$$

Therefore, as a result of the analysis, we've got realistic, optimistic and pessimistic forecasts, which are presented in Figure 5 .

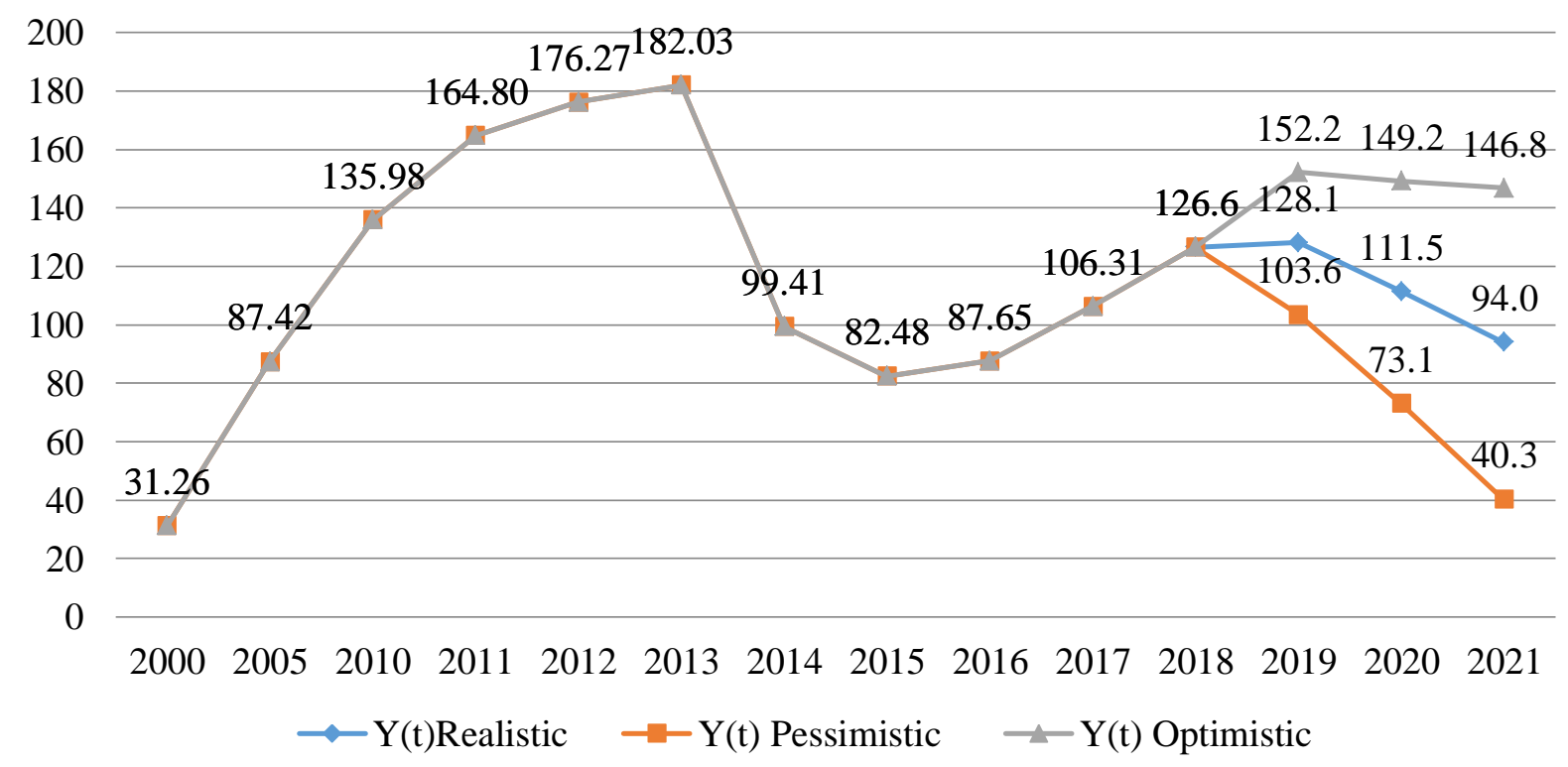

Figure 5. Ukraine's GDP forecast for 2019-2021, in billion USD

Thus, according to the results of a realistic forecast, the GDP of Ukraine in 2019 can be expected to reach $\$ 127.7$ billion, while in 2018 it has been $\$ 126.6$ billion. However, as for 2020-2021, this figure may fall to $\$ 94$ billion. It is likely that if there is the absence of positive changes, GDP may decline to 2013-2014 levels. Another important indicator demonstrating the development of demographic processes is the population. Therefore, we have to predict the development of this indicator.

According to the Ukrainian GDP forecast, we are doing the same actions according to a certain methodology. For the first model, we choose a trend of polynomial type with a confidence level of approximation of 0.9449 , and for the second one a linear trend with a confidence level of approximation of 0.9356 . 


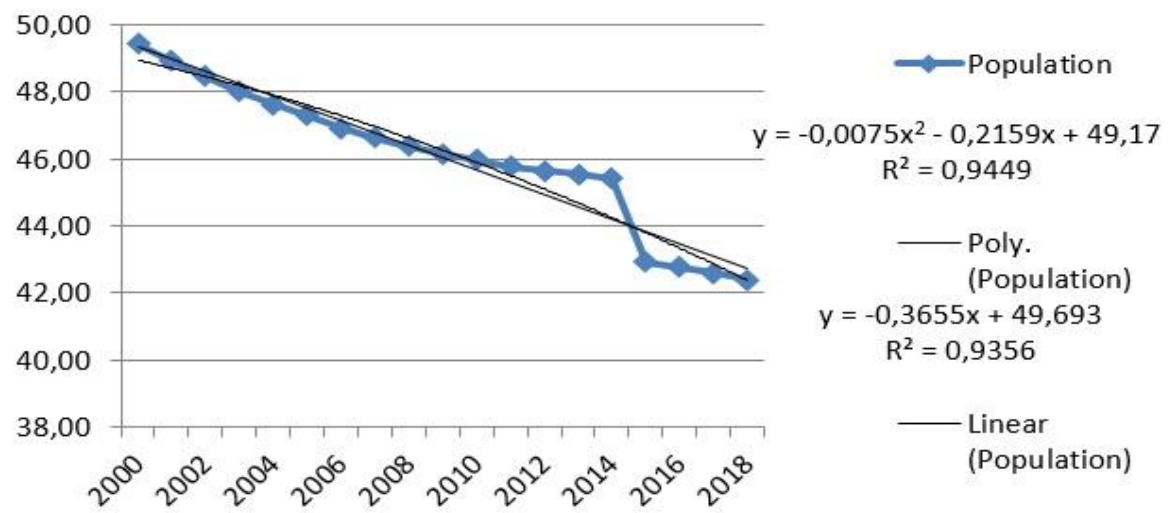

Figure 6. The Polynomial and Linear trend line of Ukrainian population

Next, we change the trend using function 1. We transfer the time into the radial measure by the function 2 . According to Bessel's functions we find bk, ak, a0 coefficients. The total number of harmonics is 9, (functions 3, 4, $5)$. We find $z^{\text {teor }}(t)$ by decomposing the cyclic component output into the Fourier series using function 6 . Having got the dependences between $z(t)$ and $z^{\text {teor }}(t)$ we visually compare them with each other.

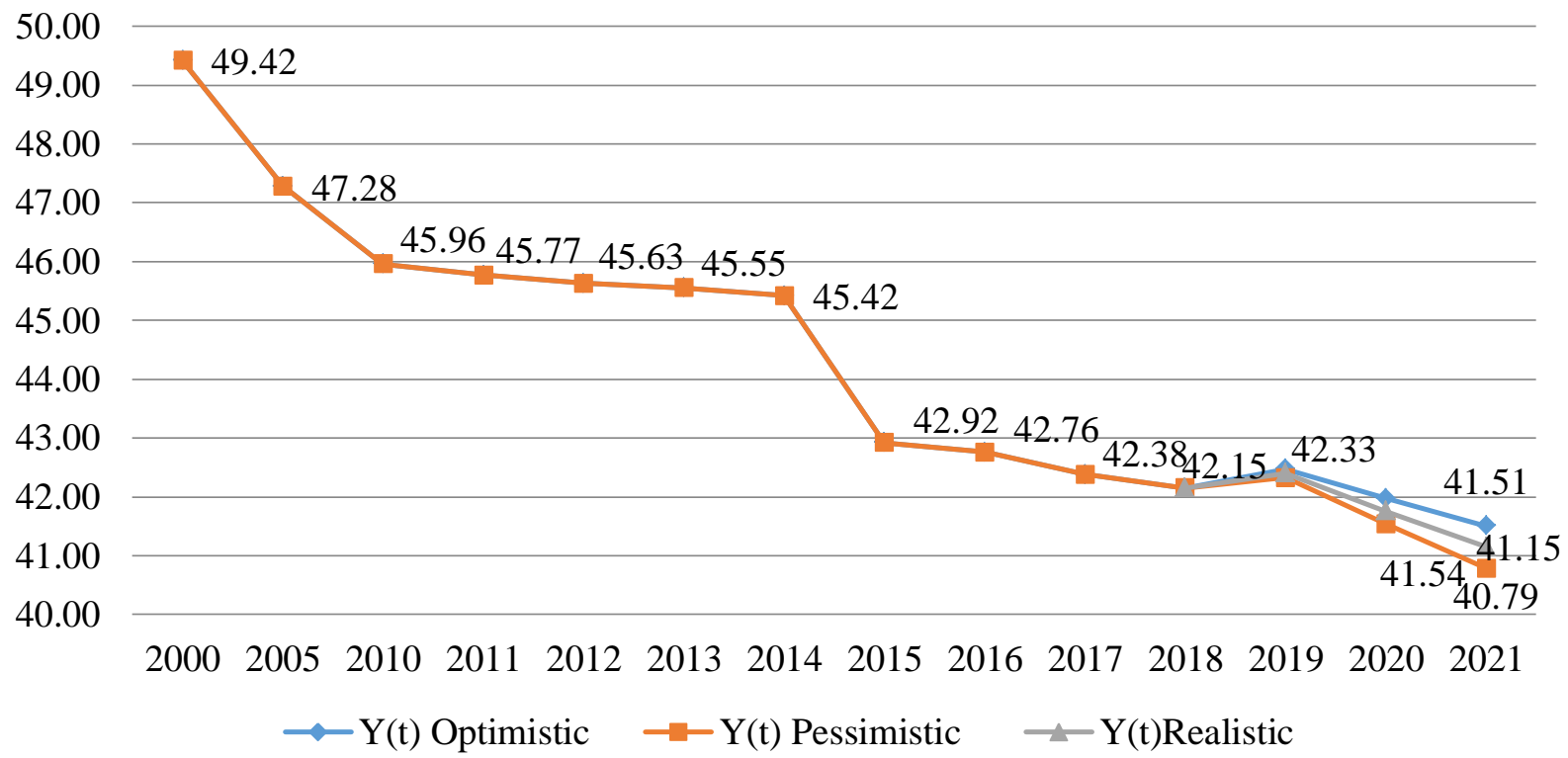

Figure 7. Population forecast in Ukraine 2019-2021

This forecast shows that the population will continue to decline. However, it is worth noting again that the forecast is based on past data and on the conditions that exist at the time when the forecast has been made, and if these conditions continue in the future, the population level will decline. Thus, we can say that hostilities cause enormous damage to the country's economy and population, besides that scare potential and existing investors to consider Ukraine's economy as a possibility to invest and gain some revenues.

\section{Conclusion}

The instability in the socio-political plane and the threat of large-scale armed aggression in the Eastern part of Ukraine lead to increased distrust of the banking system, worsen the investment climate in Ukraine, which will result in significant indirect losses in the short and medium term. Exacerbation of social and humanitarian problems, in addition to strengthening the potential of protest sentiment among the population of the country, causes an increase in the financial burden on the state budget and social funds. 
However, it should be noted that the situation can be more complicated and the amount of losses will increase significantly as a result of committing unlawful (sabotage, terrorist) actions on potentially dangerous objects and / or violation of conditions of temporary ceasefire and, as a consequence, another escalation of armed confrontation and its distribution within another territories of the country.

The obvious and most effective formula for success in the Donbas area and whole country is the implementation of effective reforms in the socio-economic sphere, which will contribute to improving the well-being, standard of living and social protection of citizens in Ukraine, and in particular in the areas adjacent to the conflict zone.

Of course, the difference in living standards of people in the territories controlled by Ukraine and in the occupied zone is a powerful impetus and is a lever of reorientation of public consciousness of the people left in the occupied regions. On the other hand, it is a powerful argument against Russian propaganda that dominates the occupied territories. In this context, it is very important to carry out comprehensive measures for the reconstruction of housing and communal infrastructure, production facilities in the surrounding regions affected by the hostilities.

\section{References}

Babenko, V., Perevozova, I., Kravchenko, M., Krutko, M., \& Babenko, D. (2020). Modern processes of regional economic integration of Ukraine in the context of sustainable development. E3S Web Conf., 166(2020), 12001. https://doi.org/10.1051/e3sconf/202016612001

Babenko, V., Pravotorova, O., Yefremova, N., Popova, S., Kazanchuk, I., \& Honcharenko, V. (2020). The Innovation Development in China in the Context of Globalization. WSEAS Transactions on Business and Economics. 17(25), 523-531. https://doi.org/10.37394/23207.2020.17.51

Gandhi, S., Foschini, L., \& Suri, S. (2010). Space-efficient online approximation of time series data: Streams, amnesia, and out-of-order. Data Engineering (ICDE), 2010 IEEE 26th International Conference on IEEE, 231-239.

Halli, S. S., \& Rao, K. V. (1992). Advanced Techniques of Population Analysis, p. 165.

Khokonov, M. Kh. (2004). Cascade Processes of Energy Loss by Emission of Hard Photons. Journal of Experimental and Theoretical Physics, 294.

Nikolić, D., Muresan, R. C., Feng, W., \& Singer, W. (2012). Scaled correlation analysis: a better way to compute a cross-correlogram. European Journal of Neuroscience. 35(5), 742-762.

Podgorna, I., Babenko, V., Honcharenko, N., Sáez-Fernández, F. J., Fernández, J. A. S., \& Yakubovskiy, S. (2020). Modelling and Analysis of Socio-Economic Development of the European Union Countries through DP2 Method. WSEAS Transactions on Business and Economics, 17(44), 454-466. https://doi.org/10.37394/23207.2020.17.44

State Statistics Service of Ukraine. (2019). Demographic and social statistics data. Retrieved from http://www.ukrstat.gov.ua/

Temme, N. M. (1996). Special Functions: An introduction to the classical functions of mathematical physics (2nd print ed.). New York: Wiley, pp. 228-231.

The Ministry of Finance of Ukraine. (2017). Foreign Direct Investment (FDI) in Ukraine. Retrieved from https://index.minfin.com.ua/ua/economy/fdi/

The Ministry of Finance of Ukraine. (2018). Expenditures of the state budget of Ukraine. Retrieved from https://index.minfin.com.ua/ua/finance/budget/gov/expense/

The Ministry of Finance of Ukraine. (2019). The national debt of Ukraine. Retrieved from https://index.minfin.com.ua/ua/finance/debtgov/

Ullah, M. I. (2013). Time Series Analysis. Basic Statistics and Data Analysis. WEN Themes, p. 457.

Weisstein, E. W. (2004). Spherical Bessel Function of the Second Kind. Integral representations of the Bessel function. Retrieved from https://www.nbi.dk

\section{Copyrights}

Copyright for this article is retained by the author(s), with first publication rights granted to the journal.

This is an open-access article distributed under the terms and conditions of the Creative Commons Attribution license (http://creativecommons.org/licenses/by/4.0/). 